УДК 316

$10.17213 / 2075-2067-2020-6-245-253$

\title{
ФЕЙКОВЫЕ НОВОСТИ КАК ФАКТОР ВЛИЯНИЯ НА ПСИХИЧЕСКОЕ ЗДОРОВЬЕ РОССИЙСКОГО НАСЕЛЕНИЯ
}

\author{
(C) 2020 г. М. А. Васьков
}

"Южный федеральный университет, г. Ростов-на-Дону, Россия "*уббанский государственный технологический университет, г. Краснодар, Россия

Целью исследования является анализ фейковых новостей как фактора влияния на психическое здоровье российского населения.

Методологическую базу исследования представляет валеологический, психолого-педагогический и гуманистически ориентированный подход к психическому здоровью населения.

Результаты исследования. Фейковые новости в СМИ (как правило, наполненные информацией негативного характера) оказывают непосредственное влияние на психическое здоровье российского населения. Главной чертой российских СМИ является доминирование негативной информации в отборе материала с активным применением фейковых новостей. К основным последствиям фейковых новостей, носящих исключительно отрицательный характер влияния на психическое здоровье населения, относятся: психофизиологические, когнитивные, аффективные, установочные, поведенческие последствия.

Перспективу исследования составляет необходимость поиска механизмов информаичинно-психологической безопасности российского населения от негативного воздействия СМИ и фейковых новостей на психическое здоровье российского населения.

Ключевые слова: фейковые новости; фейк; психическое здоровье; психика; российское население; СМИ; психофизиологические; когнитивные; аффективные; установочные; поведенческие последствия.

\section{FAKE NEWS AS A FACTOR OF INFLUENCE ON THE MENTAL HEALTH OF THE RUSSIAN POPULATION}

\author{
(C) 2020 M. A. Vaskov", A. V. Miroshnichenko*, M. A. Polivina** \\ "Southern Federal University, Rostov-on-Don, Russia \\ ${ }^{* *}$ Kuban State Technological University, Krasnodar, Russia
}

The purpose of the study is to analyze fake news as a factor influencing the mental health of the Russian population.

The methodological base of the research is a valeological, psychological, pedagogical and humanistically oriented approach to the mental health of the population.

The results of the study. Fake news in the media (usually filled with negative information) has a direct impact on the mental health of the Russian population. The main feature of the Russian media is the dominance of negative information in the selection of material with the active use of fake news. The main consequences of fake news, which have an exclusively negative impact on the mental health of the population, include: psychophysiological, cognitive, affective, attitudinal, behavioral consequences. 
The prospect of the study. The prospect of the study is the need to search for mechanisms of information and psychological security of the Russian population from the negative impact of the media and fake news on the mental health of the Russian population.

Key words: fake news; fake; mental health; psyche; the Russian population; the media; psychophysiological; cognitive; affective; attitudinal; behavioral consequences.

Введение. XXI век ознаменовался стремительным развитием информатизации, усилением влияния средств массовой информации (СМИ), реализующей, как минимум, три функции: информационную (оперативное информирование об окружающей среде); досуговую (обеспечение занимательного досуга); воспитательно-социализационную (обеспечение воспитания и социализации молодых поколений, а также социализации и ресоциализации других социальных групп) [1]. При этом, как подчеркивает Л.В. Куликов, СМИ являются «фактически главным институтом воспитания, формирования мировоззрения и массового сознания», которые, однако «не желают выполнять воспитательные функции и брать на себя ответственность в этом плане» [2, с. 2].

Трансформационные изменения традиционных моделей коммуникативных взаимодействий на уровнях «государство СМИ - общество» демонстрируют, что данные функции не просто не реализуются в адекватном формате, но и имеют дисфункциональное значение по отношению к психическому и социальному здоровью населения $[3,4]$. Это объясняется искажением в современной реальности истинности факта и фактической информации, ибо истинность фактической информации стала напрямую зависеть от того количества инвестиций, которые были вложены в ее создание, нежели от достоверности факта [5]. Как подчеркивает В.В. Дорофеева, в современных условиях тотальной «востребованности поиска мгновенных новостей» в СМИ «все более распространенным явлением становятся фейковые новости - полностью или частично выдуманная информация об определенных лицах, событиях, явлениях» [6, с. 777], причем информация, «трансформирующая человеческое сознание» [6, с. 775].

В свою очередь, трансформация сознания (психики) приводит к стагнации «в социаль- ном, духовном, культурном, политическом, научном и технологическом развитии, то есть к отставанию во всех сферах жизни, уменьшению и потере конкурентоспособности» $[2$, с. 2].

Таким образом, влияние СМИ реализуется посредством психологического воздействия на разум и эмоционально-чувственную сферу личности, ибо СМИ, как свидетельствует опыт, способны как умственно просвещать, «обогащать личность», так и «духовно порабощать, дезинформировать и запугивать население», «сеять недоверие и страх» [7, 8], причинять вред духовному, социальному и психическому здоровью [9].

В связи со сказанным выше целью данной статьи является анализ фейковых новостей как фактора влияния на психическое здоровье российского населения, и актуальность поставленной цели не вызывает сомнений.

В соответствии с заявленной целью, прежде всего, остановим взор на феномене фейковых новостей в СМИ.

Феномен фейковых новостей. Сегодня «фейковые новости» проникли во все сферы жизнедеятельности россиян, ими наполнены практически все СМИ, однако, несмотря на такую популярность использования приема фейка в новостных каналах, понятийное толкование фейка в рамках официальных словарей русского языка, лингвистики, психологии, социологии и политологии пока не представлено. Но мы встречаем понятие «фейк» в словаре компьютерных терминов, где дается такое определение: «Фейк (англ. fake /fek/) подделка, фальсификация, обман» с целью искажения определенной информации [10].

Также трактовка категории «фейк» раскрыта в онлайн Викисловаре и интерпретируется как неологизм, имеющий жаргонный контекст: «что-либо лживое, не соответствующее действительности, поддельное, вводящее в заблуждение» [11]. Интересно, что 
в Оксфордском словаре феномен «фейк» по смысловому содержанию связан с глаголами «убирать», «подметать» и заключает идею лживой информации, обмана, фальсификации, введения в заблуждение [12].

Если отталкиваться от того, что новость - это оперативное информационное сообщение о фактах, явлениях, событиях, имевших место в недавнем времени или происходящих в рамках текущего временного отрезка; это сообщение, представляющее психосоциальный, политический, социокультурный или экономический интерес для общественности «в своей свежести, то "фейковая новость” - это сообщение, стилистически созданное как настоящая новость, но ложное полностью или частично» $[13$, с. 89$]$.

С.С. Распопова и Е.Н. Богдан дают такое определение фейковым новостям: «Это сфабрикованные новостные материалы, ложь в которых распознаваема и проверяема, хотя и способна ввести в заблуждение» [14, с. 48$]$.

Согласно приведенной классификации А.П. Суходолова, выделены некоторые разновидности фейковых новостей по различным основаниям, в числе которых наибольшую опасность для сознания и психического самочувствия населения представляют:

— «новости» в зависимости от достоверности обстоятельств времени и места произошедшего явления, события («новости», преподносимые как текущие, но имевшие место в прошлом, или «новости», искажающие место произошедшего события);

- в зависимости от состава лиц, упоминаемых в «новости» (например, «новости», основанные на непроверенной информации или выставляющие второстепенных участников события как главного действующего лица);

- «новости» в зависимости от целей создания и распространения (например, «новости», создаваемые с целью дискриминации по полу, возрасту, расе, языку, социальному статусу, месту жительства, убеждениям, отношению к религии и пр. обстоятельствам; а также «новости» с целью нанесения морального или материального ущерба, с целью манипуляции);

- «новости» в зависимости от уровня восприятия достоверности информации («новости» с явным или сомнительным фейковым характером, а также мастерски сфаль- сифицированные фейки, не порождающие сомнений) [13, с. 89-93].

В целом фейковые новости, как в своей статье, посвященной семантическому анализу феномена «фейковых новостей» совершенно справедливо замечает А.П. Суходолов, «органично вписываются в концепцию пост-правды». Эта концепция «описывает или обозначает обстоятельства, при которых объективные факты являются менее важными при формировании общественного мнения, чем призывы к эмоциям и личным убеждениям» $[13$, с. 94$]$.

По нашему мнению, приведенный выше анализ фейковых новостей в современных условиях развития информационно-коммуникативных технологий объективно подтверждает явную опасность для психики и психического здоровья российского населения.

Далее, реализуя поставленную цель, нам необходимо остановиться на рассмотрении категории «психическое здоровье» с тем, чтобы затем перейти к непосредственному анализу фейковых новостей как фактора влияния на психическое здоровье российского населения.

Психолого-педагогический анализ психического здоровья. Физиологическую основу психического здоровья составляет психика, которая определяется в валеологическом словаре как «системное свойство высокоорганизованной материи (мозга), заключающееся в активном отражении субъектом объективного мира, в построении субъектом неотчуждаемой от него картины этого и саморегуляция на этой основе своего поведения и деятельности» [15, с. 180]. При взгляде на это определение возникает вопрос относительно уместности утверждения построения субъектом объективной картины мира в условиях современной реальности, изобилующей фейковыми практиками, искажающими ее.

Термином «психическое здоровье» в этом же словаре валеологических и валеопсихологических терминов и определений обозначается «состояние душевного благополучия, характеризующееся отсутствием болезненных психических проявлений и обеспечивающее адекватную условиям окружающей действительности регуляцию поведения, деятельности» [15, с. 180]. 
С позиций гуманистического подхода, который зиждется на безусловном доверии к человеческой природе, общим принципом психического здоровья является стремление всякого человека стать и оставаться самим собой, невзирая на перипетии и трудности индивидуальной и общественной жизни [16].

Как известно, сочетание нормальной взаимосвязи между реальным и идеальным «Я» служит критерием психического здоровья личности. Считается, что наличие различий в этих системах дает импульс к развитию личности, но значительные различия в этой взаимосвязи - это показатель психического нездоровья [17].

Кроме того, весьма информативным показателем психического здоровья является уровень тревожности человека [17], который сегодня, в условиях т.н. информационной пандемии, возрос. Негативно настроенное население склонно изводить себя сомнениями, тревогами, неуверенностью, плохими предчувствиями, негативными экспектациями и пессимизмом.

Фейковые новости являются своеобразным деструктивным триггерным механизмом, способствующим возникновению и развитию разнообразных психогенных расстройств или, выражаясь языком медицинской психологии, психогений - неврозов и реактивных неврозоподобных состояний, возникающих как реакция на психотравмирующую ситуацию или событие, а также вызывающих страх, тревогу, напряженность $[18,19]$.

Основное следствие превалирования деструктивной информации в СМИ состоит в том, что у населения формируется установка на «пессимистический взгляд на происходящее, возникает безверие, снижается самооценка» [2, с. 7], что в свою очередь приводит к снижению настроения и появлению отрицательного психоэмоционального фона как субъективной реакции на такую «объективную картину мира».

В соответствии с проведенным анализом научной литературы в рамках данной проблематики авторы пришли к выводу о том, что фейковые новости в СМИ (как правило, наполненные информацией негативного характера), будучи фактором влияния на психическое здоровье российского народа, оказывают непосредственное влияние на психику различных групп населения. Ибо, как показывает практика, их влияние имеет определенные последствия для психического здоровья.

\section{Какие же это последствия влияния} фейковых новостей для психического здоровья? Во-первых, это психофизиологические последствия, связанные с изменениями в психофизиологической сфере человека, к примеру, возникновение целого комплекса отрицательных эмоций возмущения, негодования, злости, фрустрации и раздражения при просмотре новостной ленты западных СМИ о событиях Второй мировой войны, основанных на фальсификации фактов, их умышленном искажении, может вызвать тахикардию (учащенное сердцебиение), реакцию кожных покровов.

Во-вторых, когнитивные последствия, изменяющие базовые знания, мышление человека. В качестве примеров, изменяющих менталитет, можно привести, во-первых, искажение, ложное описание новостей в соответствии с какой-то предвзятой идеей (сознательный отказ от стремления к истинному описанию настоящих событий); во-вторых, преимущество или выбор одних событий и преуменьшение, а то и просто замалчивание других (замалчивание фактов, их игнорирование - это вид умышленной фальсификации).

В-третьих, аффективные последствия, связанные с переживанием отрицательных эмоций, несущих психологическую травму и причиняющих душевную боль. Более того, в некоторых случаях эти эмоции способны разрушить жизнь. В качестве наглядного примера можно привести случай, когда в марте 2017 года в социальных сетях появилась информация о том, что жены военных, погибших на службе, всего лишь пытаются привлечь к себе внимание и получить 15 минут славы [20].

Современные СМИ, как справедливо замечает В.Е. Семенов, «явно и неявно действуют как средство невротизации» психики и стимулируют «агрессивные и порочные импульсы» у населения [1, с. 60]. Так, по мнению В.Е. Семенова, СМИ вносят определенный вклад в «увеличение количества убийств и самоубийств, алкоголизма, даже простого курения, а также нарастания всевозможных 
сексуальных аномалий и разнообразных психических нарушений, включая сложные садомазохистские комплексы» [1, с. 60].

В-четвертых, установочные последствия, сопряженные с установками людей и формированием определенных мнений, убеждений, изменений образа мышления в нужном для манипуляторов - создателей фейковых новостей направлении. Как только какая-либо информация распространится в социальных сетях, становится очень трудно изменить мнение людей по этому поводу. Исследования показали, что даже при наличии фактов и доказательств многие люди неохотно меняют свое мнение, когда им предоставляется корректирующая информация, а попытки насильственно исправить неправильные верования и мнения только ухудшают ситуацию. И это действительно так, ведь многие люди даже тогда, когда узнают, что были неправы, отказываются это признавать [20].

Установки так или иначе накладывают отпечаток на наше мировосприятие и его интерпретацию. При этом психическое восприятие становится ригидным, поскольку у людей уже сформировано мнение по принципу первичности информации (согласно известному стереотипу первичности восприятия, гласящему, что первичное впечатление при получении информации кажется наиболее правдивым).

В-пятых, поведенческие последствия, являющиеся следствием измененных установок, что в свою очередь, влечет за собой формирование новых паттернов поведения. Так, например, фейковые новости могут способствовать формированию фактора «выученной беспомощности», которая базируется на личной неспособности принимать решения и осуществлять рациональные действия [21].

Фейковая новость работает на психологию восприятия, как манипуляция, поскольку известно, что фейковые новости оставляют в сознании неприятный осадок даже после того, как проверка фактов проведена и подделка разоблачена [22].

Фейк, создаваемый на основе манипуляции подлинной информацией со смещением акцентов и хронологической последовательности событий, завладевает вниманием порядка 40-50\% целевой аудитории, в то время как фейк, строящийся на основе реальной информации с большой долей выдуманных подробностей влияет на восприятие уже $80 \%$ целевой аудитории [23]!

Побочные, латентные эффекты фейковых новостей, оказывающие влияние на психику, по мнению Ю.М. Ершова, оказываются гораздо тяжелее их прямого воздействия, поскольку фейковым новостям «подвержены немногие слишком уж легковерные читатели. Побочный же эффект от фейковых новостей связан с загрязнением информационной среды и поражением базового доверия аудитории в целом к сообщениям СМИ» [24, с. 246].

В целом большая часть российского населения понимает и чувствует негативное влияние СМИ и фейковой информации. Ибо, как показывает проведенный анализ, главной чертой российских СМИ является доминирование негативной информации в отборе материала с активным применением фейковых новостей [25].

Заключение. Резюмируя, важно подчеркнуть, что последствия влияния фейковых новостей на психическое здоровье разнообразны и носят преимущественно негативный характер. Основными последствиями влияния фейковых новостей на психическое здоровье населения являются: психофизиологические, когнитивные, аффективные, установочные, поведенческие последствия.

В силу того, что в современном обществе информация играет важнейшую роль в жизни населения и СМИ таят в себе сильнейший потенциал отрицательного влияния на психику и психическое здоровье российского населения, необходимо уделять серьезное внимание подлинности самой информации. Нужно учитывать, что мобилизационная функция СМИ, помимо поднятия социально-политической активности, должна состоять еще в том, чтобы способствовать решению различных социально-психологических задач, транслировать образцы профилактики психического нездоровья и преодоления духовно-нравственного кризиса, духовно-этической люмпенизации общества. В этой связи российскому (гражданскому) обществу необходимо добиваться принятия Закона о нравственном контроле в сфере СМИ в рамках концепции «Доктрины информационной безопасности». 


\section{Литература}

1. Семенов В.Е. Влияние современных российских средств массовой информации на нравственно-психическое здоровье людей// Здоровье - основа человеческого потенциала: проблемы и пути их решения. 2006. - C. 59-62.

2. Куликов Л.В. Социально-психологические аспекты влияния СМИ на сознание // Вестник Санкт-Петербургского университета. Сеp. 12. - 2011. - Вып. 1. - С. 3-12.

3. Гафиатулина Н.Х., Рачипа А.В., Самыгин С.И. Информационная сетевая среда как фактор влияния на социальное здоровье российской студенческой молодежи // Гуманитарные, социально-экономические и общественные науки. - 2018. - №1. - С. 23-27.

4. Васьков М.А., Ковалев В.В., Гафиатулина H.X. Онлайн-образование в высшей школе России: основные акторы институционализации и социальные последствия // Гуманитарий Юга России. - 2020. - Т. 9. №3. - С. 45-57.

5. Шарков Ф.И., Понеделков А.В., Вась$\kappa о в ~ M . A$. О роли политико-административных элит в инновационно-коммуникационном развитии современной России // Коммуникология. - 2019. — Т. 7. — №3. - С. 15-25.

6. Дорофеева В.В. Фейковые новости в современном медиапространстве // Вопросы теории и практики журналистики. 2019. - T. 8. - №4. - С. 774-786.

7. Радченко Л.Е. Влияние информации на нравственное, психическое здоровье и воспитание подрастающего поколения// Материалы Афанасьевских чтений. - 2016. C. 215-223.

8. Shakhbanova M.M., Kasyanov V.V., Gafiatulina N. Kh., Gluzman I.V., Polivina M.A., Gnatyuk M.A., Ramazanov R.O. The role of trust in the formation of ethnic tolerance and social health in the modern Russian society // Revista Inclusiones. - 2019. - Vol. 6. - №2. P. 296-305.

9. Vaskov M., Rezvanov A., Kasyanov V., Samygin S., Gafiatulina N., Zagutin D., Scherbakova $L$. Value orientations of russian youth in the system of managing the moral security of society (2018) [Electronic resource] // Herald National Academy of Managerial staff of culture and arts. - 2018. - №2. - P. 134-140. - URL: http://heraldnamsca.in.ua/index.php/hnamsca/ article/view/309.

10. Словарь компьютерных терминов [Электронный ресурс]. - Режим доступа: https://computer.slovaronline.com/1187-FEYK.

11. Викисловарь [Электронный ресурс]. - Режим доступа: https://ru.wiktionary. org/wiki/фейк.

12. The Oxford English Dictionary. - Oxford: Oxford University Press, 1989. - Vol. 20.

13. Суходолов А. П. Феномен «фейковых новостей» в современном медиапространстве// Евроазиатское сотрудничество: гуманитарные аспекты. - 2017. — №1. - С. 87-106.

14. Распопова E. С., Богдан Е.Н. Фейковые новости: природа происхождения // Вестник Челябинского государственного университета. - 2017. - Вып. 109. - С. 48-53.

15. Колбанов В. В. Валеология: основные понятия, термины и определения. - СПб., 2010. - $256 \mathrm{c}$.

16. Шувалов А.В. Психологическое здоровье человека // Вестник Православного Свято-Тихоновского гуманитарного университета. - 2009. - Вып. 4 (15). - С. 87-101.

17. Денисова Е.А., Кузьмичев С.А., Чапала Т.В., Мальшева И.В. Психология здоровья: электронное научное издание. - Тольятти, 2017. - 107 с.

18. Абакумова И.В., Мирошниченко А.В., Дмитриев Ю. Ю. Экспресс-диагностика социальной напряженности, агрессивности, враждебности пользователей интернет в контексте предупреждения и противодействия терроризма // Казанский педагогический журнал. 2015. — №6-3 (113). - C. 167-170.

19. Miroshnichenko A.V. Psycchological studies of information culture and peculiarities of value-value sphere among students working with information technologies // North-Caucasian Psychological Journal. - 2009. - №3. P. 38.

20. Как фейковые новости влияют на нашу повседневную жизнь? [Электронный ресурс]. - Режим доступа: https://fb.ru/ post/psychology/2017/7/3/14656.

21. Мирошниченко А. В., Алексеенко И. Н., Гаглоева Э.Н. Использование инновационных и дистанционных технологий в учебном процессе высшей школы // Вестник ЮжноРоссийского государственного технического университета (Новочеркасского политехни- 
ческого института). Серия: Социально-экономические науки. - 2020. - Т. 13. - №4. C. 22-30.

22. Гафиатулина Н.Х., К Касьянов В.В., Самызин П.С., Самызин С.И. Российское общество в условиях самоизоляции. Социальные эффекты и последствия пандемии Covid-19. Монография. - Москва, 2020.

23. Красовская Н. Жизнь в эпоху постправды [Электронный ресурс]. - Режим доступа: https://www.pravda.ru/science/1473851feik_seti/.

24. Ершов Ю.М. Феномен фейка в контексте коммуникационных практик // Вестник Томского государственного университета. - 2018. - №52. - С. 245-256.

25. Ольховский К. А., Суслонов П.Е. Фейк в информационном дискурсе // Инновационный потенциал молодежи: социальная, экологическая и экономическая устойчивость. 2018. - C. 199-202.

\section{References}

1. Semenov V.E. Vlijanie sovremennyh rossijskih sredstv massovoj informacii na nravstvenno-psihicheskoe zdorov'e ljudej [Influence of modern Russian mass media on moral and mental health of people] // Zdorov'e - osnova chelovecheskogo potenciala: problemy i puti ih reshenija [Health - the basis of human potential: problems and ways of their solution]. 2006. - Pp. 59-62.

2. Kulikov L.V. Social'no-psihologicheskie aspekty vlijanija SMI na soznanie [Sociopsychological aspects of the influence of mass media on consciousness] // Vestnik Sankt-Peterburgskogo universiteta. Ser. 12. - 2011. - Issue 1. - Pp. 3-12.

3. Gafiatulina N.H., RachipaA.V., Samygin S. I. Informacionnaja setevaja sreda kak faktor vlijanija na social'noe zdorov'e rossijskoj studencheskoj molodezhi [Information network environment as a factor of influence on the social health of russian student youth] // Gumanitarnye, social'no-jekonomicheskie i obshhestvennye nauki [Humanities, socio-economic and social sciences]. - 2018. — №1. - Pp. 23-27.

4. Vas'kov M. A., Kovalev V.V., Gafiatulina N.H. Onlajn-obrazovanie v vysshej shkole Rossii: osnovnye aktory institucionalizacii i social'nye posledstvija [Online education in the higher school of Russia: the main actors of institutionalization and social consequences] // Gumanitarij Juga Rossii [Humanities of the South of Russia]. - 2020. - Vol. 9. - №3. - Pp. 45-57.

5.Sharkov F.I., Ponedelkov A. V., Vas 'kovM.A. $\mathrm{O}$ roli politiko-administrativnyh jelit $\mathrm{v}$ innovacionno-kommunikacionnom razvitii sovremennoj Rossii [On the role of political and administrative elites in the innovation and communication development of modern Russia] // Kommunikologija. - 2019. - Vol. 7. - №3. Pp. 15-25.

6. Dorofeeva $V . V$. Fejkovye novosti v sovremennom mediaprostranstve [Fake news in the modern media space] // Voprosy teorii i praktiki zhurnalistiki [Questions of theory and practice of journalism]. — 2019. - Vol. 8. — №4. Pp. 774-786.

7. Radchenko L.E. Vlijanie informacii na nravstvennoe, psihicheskoe zdorov'e i vospitanie podrastajushhego pokolenija [Influence of information on moral, mental health and education of the younger generation] // Materialy Afanas'evskih chtenij [Materials of the Afanasiev's readings]. - 2016. - Pp. 215-223.

8. Shakhbanova M.M., Kasyanov V.V., Gafiatulina N. Kh., Gluzman I.V., Polivina M.A., Gnatyuk M.A., Ramazanov R.O. The role of trust in the formation of ethnic tolerance and social health in the modern Russian society // Revista Inclusiones. - 2019. - Vol. 6. - №2. P. 296-305.

9. Vaskov M., Rezvanov A., Kasyanov V., Samygin S., Gafiatulina N., Zagutin D., Scherbakova $L$. Value orientations of russian youth in the system of managing the moral security of society (2018) [Electronic resource] // Herald National Academy of Managerial staff of culture and arts. - 2018. - №2. - P. 134-140. - URL: http:/heraldnamsca.in.ua/index.php/hnamsca/ article/view/309.

10. Slovar' komp'juternyh terminov [Dictionary of computer terms] [Jelektronnyj resurs]. — URL: https://computer.slovaronline. com/1187-FEYK.

11. Vikislovar' [Wiktionary] [Jelektronnyj resurs]. — URL: https://ru.wiktionary.org/wiki/ fejk.

12. The Oxford English Dictionary. - Oxford: Oxford University Press, 1989. - Vol. 20.

13. Suhodolov A.P. Fenomen «fejkovyh novostej» $\mathrm{V}$ sovremennom mediaprostranstve 
[The phenomenon of «fake news» in the modern media space] // Evroaziatskoe sotrudnichestvo: gumanitarnye aspekty [Eurasian cooperation: humanitarian aspects]. - 2017. - №1. Pp. 87-106.

14. Raspopova E.S., Bogdan E.N. Fejkovye novosti: priroda proishozhdenija [Fake news: nature of origin] // Vestnik Cheljabinskogo gosudarstvennogo universiteta [Bulletin of the Chelyabinsk State University]. — 2017. — Issue 109. - Pp. 48-53.

15. Kolbanov V.V. Valeologija: osnovnye ponjatija, terminy i opredelenija [Valeology: basic concepts, terminology and definitions]. Saint-Petersburg, 2010. - $256 \mathrm{p}$.

16. Shuvalov A.V. Psihologicheskoe zdorov'e cheloveka [Psychological health of a person] // Vestnik Pravoslavnogo SvjatoTihonovskogo gumanitarnogo universiteta [Bulletin of the Orthodox St. Tikhon's University for the Humanities]. — 2009. - Issue 4 (15). Pp. 87-101.

17. Denisova E.A., Kuz'michev S. A., Chapala T.V., Malysheva I. V. Psihologija zdorov'ja: jelektronnoe nauchnoe izdanie [Psychology of health: electronic scientific publication]. Tol'jatti, 2017. - $107 \mathrm{p}$.

18. Abakumova I.V., Miroshnichenko A.V., Dmitriev Ju. Ju. Jekspress-diagnostika social'noj naprjazhennosti, agressivnosti, vrazhdebnosti pol'zovatelej internet $\mathrm{v}$ kontekste preduprezhdenija i protivodejstvija terrorizma [Express-diagnostics of social tension, aggressiveness, hostility of Internet users in the context of prevention and counteraction of terrorism] // Kazanskij pedagogicheskij zhurnal [Kazan Pedagogical Journal]. 2015. - №6-3 (113). — Pp. 167-170.

19. Miroshnichenko A.V. Psycchological studies of information culture and peculiarities of value-value sphere among students working with information technologies // North-Caucasian Psychological Journal. — 2009. — №3. P. 38.
20. Kak fejkovye novosti vlijajut na nashu povsednevnuju zhizn'? [How does fake news affect our daily lives?] [Jelektronnyj resurs]. - URL: https://fb.ru/post/psychology/2017/7/3/14656.

21. Miroshnichenko A.V., Alekseenko I.N., Gagloeva Je. N. Ispol'zovanie innovacionnyh i distancionnyh tehnologij $\mathrm{v}$ uchebnom processe vysshej shkoly [The use of innovative and remote technologies in the educational process of higher education] // Vestnik Juzhno-Rossijskogo gosudarstvennogo tehnicheskogo universiteta (Novocherkasskogo politehnicheskogo instituta). Serija: Social'no-jekonomicheskie nauki [Bulletin of the South Russian State Technical University (Novocherkassk Polytechnic Institute). Series: Social and economic sciences]. 2020. - Vol. 13. — №4. - Pp. 22-30.

22. Gafiatulina N. H., Kas'janov V. V., Samygin P.S., Samygin S. I. Rossijskoe obshhestvo v uslovijah samoizoljacii. Social'nye jeffekty i posledstvija pandemii Covid-19. Monografija [Russian society in the conditions of self-isolation. Social effects and consequences of the Covid-19 pandemic. Monograph]. - Moscow, 2020.

23. Krasovskaja N. Zhizn' v jepohu postpravdy [Life in the post-truth era] [Jelektronnyj resurs]. - URL: https://www.pravda.ru/ science/1473851-feik seti/.

24. Ershov Ju. M. Fenomen fejka v kontekste kommunikacionnyh praktik [The phenomenon of fake in the context of communication practices] // Vestnik Tomskogo gosudarstvennogo universiteta [Bulletin of the Tomsk State University]. - 2018. - №52. - Pp. 245-256.

25. Ol'hovskij K. A., Suslonov P.E. Fejk v informacionnom diskurse [Fake in information discourse] // Innovacionnyj potencial molodezhi: social'naja, jekologicheskaja i jekonomicheskaja ustojchivost' [Innovative potential of youth: social, environmental and economic sustainability]. - 2018. — Pp. 199-202. 

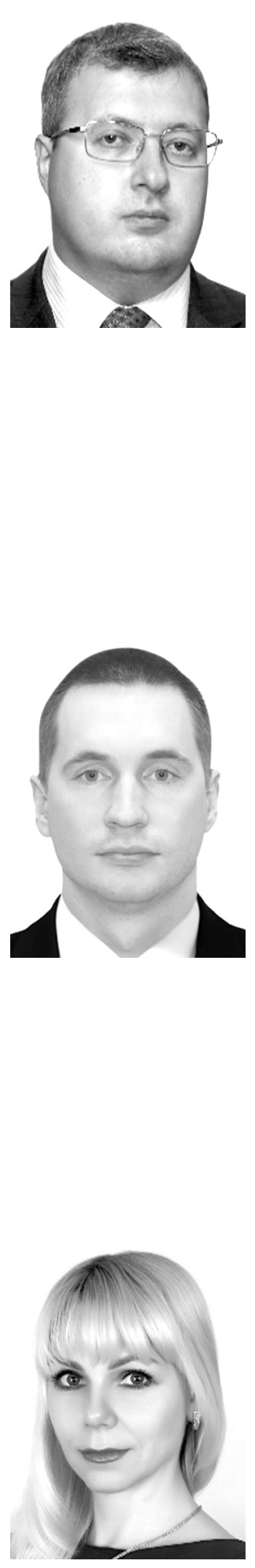

Васьков Максим Александрович - доктор социологических наук, профессор АПП, главный научный сотрудник научноисследовательской лаборатории теории и практики образования и развития лиц с особыми образовательными потребностями Южного Федерального университета.

Vaskov Maksim Aleksandrovich - Doctor of Sociological Sciences, Professor of APP, Chief Researcher of the Research Laboratory of Theory and Practice of Education and Development of Persons with Special Educational Needs, South Federal University.

344038 , г. Ростов-на-Дону, ул. Нагибина, 13

13 Nagibina st., 344038, Rostov-on-Don, Russia

E-mail: mavaskov@sfedu.ru

Мирошниченко Александр Владимирович - кандидат психологических наук, заведующий кафедрой общей и педагогической психологии Южного Федерального университета.

Miroshnichenko Aleksandr Vladimirovich - Candidate of Psychological Sciences, Head of the Department of General and Educational Psychology, Southern Federal University.

344038, г. Ростов-на-Дону, ул. Нагибина, 13

13 Nagibina st., 344038, Rostov-on-Don, Russia

E-mail: akmrgu@mail.ru

Поливина Марина Анатольевна - кандидат исторических наук, доцент кафедры гуманитарных дисциплин Армавирского механико-технологического института (филиала) Кубанского государственного технологического университета.

Polivina Marina Anatolyevna - Candidate of Historical Sciences, Associate Professor, Department of Humanities, Armavir Institute of Mechanics and Technology (branch) of Kuban State Technological University.

352905, г. Армавир, ул. Кирова, 127

127 Kirova st., 352905, Armavir, Russia

E-mail:marina_polivina@mail.ru 